\title{
Erratum to: Phenomenological Fingerprints of Four Meditations: Differential State Changes in Affect, Mind-Wandering, Meta-Cognition, and Interoception Before and After Daily Practice Across 9 Months of Training
}

Bethany E. Kok ${ }^{1}$ - Tania Singer ${ }^{1}$

Published online: 22 October 2016

(C) Springer Science+Business Media New York 2016

Erratum to: Mindfulness

DOI 10.1007/s12671-016-0594-9

The colors identifying "Breathing meditation" and "Body Scan" were unfortunately switched in the figure relative to the legend. The correct Figure 2 is below.

The online version of the original article can be found at http://dx.doi. org/10.1007/s12671-016-0594-9.

Bethany E. Kok

bethkok@cbs.mpg.de

Department of Social Neuroscience, Max Planck Institute for Human Cognitive and Brain Sciences, Stephanstraße 1A,

04103 Leipzig, Germany 
Cube of Thought

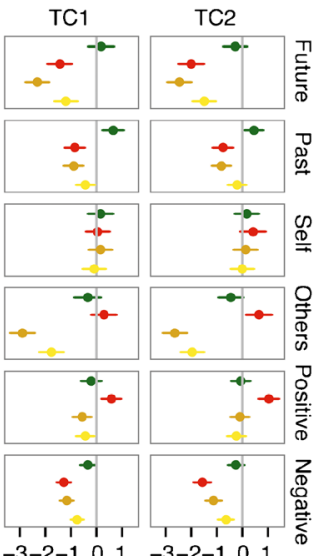

Breathing meditation
Feeling States



Body Scan
Loving-kindness meditation

\section{Meta-Cognition}

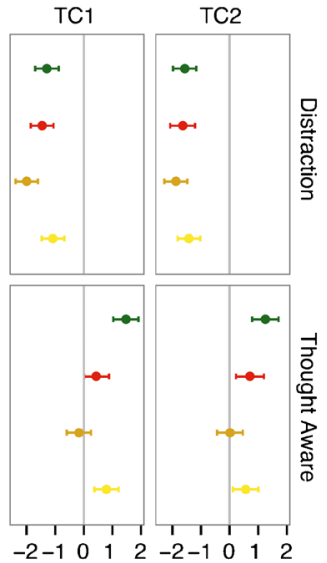

Observing-thoughts meditation

Fig. 2 Estimates and $95 \%$ confidence intervals for model-derived state changes in the four mental training practices of training cohorts 1 and 2 